\title{
E-Voting vs E-Trust: A test bed for e-Democracy in a World in Crisis?
}

\author{
Fouad Shat ${ }^{1}$ and Elias Pimenidis ${ }^{2}$ \\ ${ }^{1}$ Brunel University, London, United Kingdom \\ Fouadjf.shat@Brunel.ac.uk \\ ${ }^{2}$ University of the West of England, Bristol, United Kingdom \\ Elias.Pimenidis@uwe.ac.uk
}

\begin{abstract}
The world is currently experiencing a number of real challenges in the face of persistent economic crisis, local conflicts and huge waves of refugees. All of the above are affecting secure access to, completion of peoples' voting rights and participation in Democratic processes in their homeland. The relevant technological solutions appear to have matured and have successfully responded to rigorous testing. The need for digital access to election events is today higher than ever in the digital age. The question that remains to be answered is whether all this is enough to inspire people to trust the systems and participate in e-voting; particularly in areas where the political climate might be volatile and Trust is a rare commodity. The authors present the outcome of a survey among the Palestinian diaspora to gauge their trust and willingness to use e-voting systems in the Palestinian Authority's elections. This work does not consider political implications or even the willingness of a specific government to embrace e-voting for conducting elections.
\end{abstract}

Keywords. e-Voting; e-Trust; e-Democracy; Refugees; Digital Elections; World Crisis; eVoting Technologies; Palestine

\section{Biographical notes:}

Fouad Shat is a PhD candidate at Brunel University in the UK, pursuing research in EGovernance. His research has been inspired by the continuous effort to support his homeland of Palestine in organizing services and improving living and service conditions for Palestinians across the world. The outcome of his work has been widely published in the proceedings of high quality International Conference and in reputable International Journals. His other qualifications include a Bachelor of Engineering (BEng) in Computer Technology/Computer Systems Technology (Al-Azhar University, Palestine) and an MSc in Innovative Technology (University of East London, UK).

Elias Pimenidis is a Senior Lecturer in Computer Science at the University of the West of England in the United Kingdom. His research spans a number of topic areas, Electronic Governance, Web Services, Security, Neural Networks and Collaborative Filtering. Before 
becoming a full time academic he has spent ten years in the manufacturing industry and his research often focuses on problems inspired by challenges facing the modern manufacturing world. More recently his attention has been drawn to research that aims to utilise state-ofthe-art technologies to deliver e-services that support the democratization of war-torn countries and their people.

\section{Introduction}

The world is currently experiencing a number of serious challenges in the face of persistent economic crisis, local war conflicts and huge waves of refugees. Europe in particular has experienced a massive arrival of people seeking asylum as refugees from wars and terrorist atrocities taking place primarily in Asian countries. As governments and Non-GovernmentOrganizations (NGO) together, are struggling to address the basic needs of these very large numbers of displaced people, other equally important administrative and longer term management issues arise and need to be considered (The Guardian, 2016). Such issues are the proper registration and efficient administration of the refugees / asylum seekers to allow them to be accounted for and to be introduced to services that would enable them to enter a normal phase in their new lives. At the same time governments in particular, both at the new countries of settlement and back at their home countries need to establish a means for the refugees to continue to engage and participate in the process of re-democratisation of their countries of origin. This concept, that might appear too optimistic and far too futuristic while authorities across Europe are overwhelmed at the heart of the crisis, could possibly offer a multifaceted solution for all parties involved. It might benefit, the refugees, the countries of arrival and their countries of origin in overcoming the effects of the crisis. The authors are exploring the potential of e-voting systems as a means of assisting the redemocratisation of countries that have been ravaged by war and have lost a large number of citizens to other countries as refugees. Such systems can be utilized in keeping the refugees engaged in democratic developments in their own countries, participate in democratic elections and possibly support them in establishing a route back to their homeland.

E-participation is a considerable challenge for all involved and despite e-government technologies entering their third decade of official engagement, in a large number of administrations in the developed and the developing world; there is still progress to be made.

While focusing on literature relevant to e-voting the researcher will come across a large number of publications claiming that the relevant technological solutions have matured and have successfully responded to rigorous testing. The need for digital access to election events is today higher than ever in the digital age. The question that remains to be answered is whether all this is enough to inspire people to trust the systems and participate in evoting. This is particularly critical in areas where the political climate might be volatile and Trust is a rare commodity.

To this effect the authors have considered the case of a land that has experienced turmoil for a number of decades now and has seen its people disperse throughout the world, Palestine. Considering the diaspora of Palestinians across the world, it has been frequently proposed over the past few years that engaging e-voting systems in the elections for government in the Palestinian Authority will offer better democratic representation and enhance the perceived legitimacy of the government as it seeks state recognition. Although the political complexity of the situation in Palestine is higher than that of a lot of states where present day refugees originate, the authors feel it is an established and mature case for the research presented here. A questionnaire survey has been conducted reaching 
Palestinians across the world and capturing their opinion as to the potential of using and primarily trusting e-voting systems in the case of elections for the Palestinian Authority government. The results of this survey are presented and discussed in section 4 of the paper. In section 2 the authors discuss the concepts of e-democracy and e-participation, while section 3 presents relevant work from researchers that assess the usefulness of state of the art e-voting systems.

\section{E-Democracy and E-Participation}

The term "e-democracy" has emerged in discussions by scholars and politicians well before the relatively recent revolution in ICT and e-government systems, as early as the 1960s. It was part of the rhetoric about various technological utopias which rely on the use of the internet or other networks to maintain access to political information and the participation of citizens in the political life (Tsagarousianou et al, 1998). Although e-democracy might be widely understood as the participation of citizens in elections using electronic means, it is not limited to the process of elections by any means. In this context, e-democracy could include the attempts of various stakeholders including governments, political parties, civil society, organizations and activists groups to use information technologies as a means of communicating with citizens and to facilitate the exchange of information. In this sense, edemocracy can refer to any political activity that involves the use of ICT as a means of enhancing and delivering a more effective democratic process. Thus, e-democracy is effectively interrelated with and often misinterpreted as one aspect of e-government.

Despite having developed systems that appear attractive and promise effectiveness and efficiency in the provision of services, governments and administrations have to ensure commitment at all levels to attract and enhance citizen engagement. Governments need to adapt structures and decision-making processes to ensure that the results of online consultations are analysed, disseminated and utilized. Equally, changes to procedures through which services are delivered will offer much desired transparency and can improve the trust of citizens in systems. Governments have to communicate their commitment widely, demonstrate it in practice, put it to test and have it validated regularly. Building commitment and capacity can be based on the experience gained by local governments, parliaments and other countries. Local customs, values and citizens expectations have to be considered, continuously monitored and embedded on the design and review of egovernment systems (OECD 2003, Pimenidis and Georgiadis 2014).

With the development of ICT and their use in governmental contexts, e-trust has emerged as a term specifically referring to the trust of citizens in services offered by their governments through digital means of communication. With the passage of time and the evolution of technological advancements, e-trust has nowadays become one of the most important aspects to be considered in all stages of planning, implementing or assessing of egovernment services and a key factor in citizen engagement and participation in egovernment contexts.

Certain countries have experienced effective e-government facilities and have emerged in the true context of e-democracy with access to public services and communications with prevalence to the government institutions. E-trust has been cultivated through government transparency and has instigated new opportunities for these countries; enabling them to assess the problems and the hindrances affecting the governmental service structure through the application and adaptation of digital transactions on a wide scale. Besides, the incorporation of e-trust along with e-government services has enriched the efficacy and viability of governments in upgrading their services towards their citizens and public institutions (Casati, 2009). Other researchers have claimed that overall economic development of a country depends on e-democracy and e-trust prevailing in such a country. The overall economic development witnessed in a country can be measured by the e- 
government facilities as well as the synchronized e-democratic services and e-trust services through internet facilities and services (Celeste, et al., 2006).

Mukhametzhanova et al. (2014) focus on the differing economic histories and types of government administrations of various countries. They cite central Asian democracies like Kazakhstan which has traditionally followed a central administration system, as opposed to the UK which has over the years developed a much devolved government system with decision making often delegated to lower levels of authority at local government level. Thus in the case of the centralized government model of Kazakhstan public servants and citizens expect the government to issue very specific instructions with detailed actions and timescales to be implemented. In contrast, in the United Kingdom minutes of meetings are passed to relevant people or bodies that have to act and the expectation is for these persons to read the minutes and reach decisions. The same authors also suggest that differences in the quality of telecommunications and the density of the population can affect the level of engagement with e-government services; hence e-engagement and an e-democracy ethos can evolve in a country at a level reflecting the country's infrastructure. This last point relating to technological infrastructure though is not necessarily applicable to all cases, particularly where necessity can lead to effective solutions without the use of state of the art technologies. Pimenidis et al (2009) had reviewed and discussed a number of cases in the developing world and had found that the state of telecommunications in a country or even the density of the population might not have a direct effect on access to services. What dictates the level of engagement with online services is the necessity and the benefits accrued. Often the cost of making these services available and the cost of using them can be a decisive factor, but this would have more bearing if these services were privately sourced. In the case of e-government services the benefit has to be considered along with the potential for performance improvement and that of an increase in citizen participation and engagement.

Quental and Borges Gouveia (2014) highlight a further issue that might upstage the whole concept of e-participation and e-democracy; that of citizen disappointment in the representative government. These authors express the view that citizens believe that in the era of digital services they should be offered more opportunity to engage with decisionmaking and to participate more actively in government planning and actions that affect present life and the future of a country or a small local entity. According to these authors voters find the representative system boring and they cite participation levels in elections in Portugal as an indicative phenomenon of disinterested and disappointed citizens. They propose an e-participation platform that would allow citizens to engage more actively in decision-making and in the direct evaluation of government actions, leading to more transparency and higher citizen control.

Going a step further towards the ultimate goal of e-democracy Mukhametzhanova et al. (2014) suggest that depending on the level of basic literacy, but computer literacy too, countries can make more brave steps in developing their own clouds (G-clouds) to support virtual access to a widened variety of government services and expand on the level of edemocracy achieved. These ideas are consistent with the direction taken by the European Union (EU) in supporting cross border e-identification systems and access to services across the EU regardless of location or nationality. Such systems assume the development of trust (e-trust) between citizens and government and could potentially lead to the ultimate reality of e-democracy (Sideridis et al., 2015). Thus the quality of services, their transparency and benefits to be accrued will attract citizens and overcome fatigue in the present system of representative democracy.

\section{E-voting Systems}


E-voting systems have been developed with the aim to improve the election process by reducing costs, making the preparation of the events and the completion and issuing of the results of the vote count faster and more efficient. At the same time such systems are expected to increase voter participation from various underrepresented social groups including voters that face considerable physical barriers and voters that reside away from the country where the elections are taking place. More importantly, in the cases of elections in areas with various problems involving the authorities, e-voting systems can be utilized to verify the validity of the results obtained, ensuring that no manipulation has affected the outcome (Aumann and Lindell, 2010). E-voting systems have evolved significantly since their early days but despite their wide utilization in elections, primarily in the developed world, technical issues still persist. Kiayias et. al. (2015) discuss a flaw in one of the most widely used e-voting systems, Helios, that could potentially compromise voter privacy. These authors provide guidelines and countermeasures to be taken by an Election Authority that manages the e-voting system to ensure voter privacy and hence trust in the system and the validity of the results is achieved. The above authors propose work that aims to improve the encryption process and schemes to be employed and applied by the Election Authority.

In any e-voting system there is an important trade-off to manage. On the one hand, the system must guarantee that the action of citizen (the choice of the voter) is kept anonymous, at least to be sure that it is actually free from conditioning, while at the same time the powerful knowledge that can be obtained by relating opinions with information about people should not be missed. Such information will be vital to allow a government to analyse the need of communities and to coherently direct executive action to benefit local or wider communities according to their needs. Thus while maintaining privacy, the uniqueness of the choice of the voter; the verifiability should not be lost. Furthermore robustness and scalability are essential requirements in an e-voting system, as citizens' opinions will form the essential message that collectively evolves following an election process and deliver it to any government or authority that is the recipient of the outcome of the vote (Buccafurri et. al., 2015).

Such trade-offs can have a direct impact on real cases where citizen participation is low and the governments or other authority needs to enhance citizen engagement as a measure of their acceptability and to ensure that any decision reached will be received favourably by the public (Quental and Borges Gouveia, 2014). Examples of such cases could be the preliminary evaluation of a law or a reform, a political party poll, a satisfaction survey, a primary election, just to mention a few.

A quite challenging situation occurred with problems in the e-voting system employed by the opposition political party in Greece in 2015. In approaching the elections for a new party leader in November 2015 the election was called off due to issues with the e-voting system (e-kathimerini.com, 2015). When the elections were finally held the number of party members that turned up to vote were considerably less than on previous occasions. Although no one disputed the result of the elections there were observers that queried whether shaken trust in the system might have affected turnout and eventually the outcome of the vote.

In all cases, e-voting systems could enable the possibility of analysing the results by correlating them with information about citizens, like job, age, religion, salary, region, etc. providing essential strategic information, whose importance is comparable to that of the opinions themselves. For this though to happen privacy of the individual voter must be guaranteed otherwise the trust in the system will evaporate.

An interesting example to consider is that of opinions being expressed in the case of a preliminary evaluation of a reform. The analysis of the socio-economic composition of the survey result can be used to drive the modification of the reform in a more effective way than taking into account only the survey result itself. This would certainly empower the 
citizens involved and will attract participation, making the result more representative and at the same time more effective.

The above example is a trade-off between security and privacy needs and opinion analysis opportunities; it is certainly not a trivial issue.

To avoid considerable overheads of dedicated infrastructures, that could lead to increased cost overheads and to complexity of the system's implementation, Buccafurri et. al., (2015) proposed a method that guarantees the security requirements through the use of preexistent social networks with citizens voting through their user profiles.

Such an approach can eliminate the need for complex overheads as all is required is an electronic card to identify a citizen, or any identity management system able to identify individuals uniquely and owing a profile by each voter in one of the existing social networks. The solution, among the features typically satisfied in e-voting systems, guarantees uniqueness, privacy, verifiability, uncloneability, robustness and scalability. Unfortunately, the lightweight e-voting approach referred above, being designed according to standard requirements, cannot address the additional problem of preserving privacy during opinion analysis. Indeed, privacy inhibits the possibility to relate the preferences expressed by citizens even to non-identifying attributes.

The emergence of new forms of citizen participation in political activity through ICT has attracted attention from both research and practitioner communities, as shown by the increase in government-initiated e-participation projects at all levels across the developed world. In the past decade, following an initial phase characterized by experimentation, initiatives for e-participation have started to consolidate. Recently an increase in the degree of achievement of sustainable combinations between legacy and emerging technologies for citizen participation has given new impetus for continued growth.

Several attempts to implement systems that support e-participation have been proposed, experimentally implemented and pilot tested successfully. Quental and Borges Gouveia

(2014) proposed a Web based application designed to monitor and discuss the government activity and the proposal and implementation of new laws at national, regional or local level in Portugal.

A key question of building trust in the citizen body remains regardless of the society under consideration, its background and the state of the country's economy - developed or developing. Imperfection in an e-voting system is likely to create public distrust of the process and the results of an election, which could lead to a re-election. Distrust of a sustainable society can ultimately affect the stability of the political, economic and social environment in a nation and endanger the course of the country and the safety of its people (Kim et. al., 2015).

To avoid excessive costs of implementation Buccafurri et. al., (2015) propose, to utilize existing infrastructures and existing state of the art authentication systems already in use and trusted by citizens. The right to vote can be obtained collaboratively from a number of credential issuers. These could be government controlled or government verified systems that have been implemented with maximum security and privacy as the key requirements in their design. Such systems will eventually integrate with cross-border identification systems developed by European Union (EU) wide research and task force groups to enable access not only to local systems and services in one country but across the EU. These systems offer the added benefit of not allowing individual authorities to interfere with the levels of security and privacy of a user and thus the effectiveness and attractiveness of such systems will be paramount. Full scale adoption would certainly overcome user fears and greatly enhance eparticipation (Sideridis et. al., 2015).

\section{The case of e-voting in Palestine}




\subsection{Palestine - background and brief history:}

Palestine is a geographical region in Western Asia between the Mediterranean Sea and the Jordan River. It is sometimes considered to also include adjoining territories. Situated at a strategic location between Egypt and Jordan, The boundaries of the region have changed throughout history. Until the early twentieth century, Palestine was under the rule of the Ottoman Empire. During the First World War, Britain promised to support "complete and final liberation" for the people of the wider region in return for them rebelling against the Ottomans (PSC 2014).

In 1947 Britain approached the newly founded and then Western-dominated UN to determine Palestine's future. Despite the Jewish population only making up to a third of residents, the report recommended creating a Jewish state on $56 \%$ of the land in Palestine. The Palestinians refused to accept the division of their homeland, yet in 1948 Israel was established unilaterally. This has resulted in a wide geographical spread of Palestinian people. After this spread Israel became the ruler of more than $78 \%$ of the land. The remaining land (22\%) called West Bank, Gaza Strip and East Jerusalem have been under an illegal Israeli military rule since they were occupied in the 1967 war, and today are referred to as the "Occupied Palestinian Territories" (PSC 2014).

The Arab League Summit had created an organization called Palestinian liberation Organization (PLO) in 1964 for the purpose of liberating Palestine and creating a state for its people. Later PLO was recognized as the sole legitimate representative of the Palestinian people by many countries (United Nations 2014). In 1993, Israel and the PLO had signed the Oslo accord. This agreement offered Palestinians self-determination which has resulted in the formation of a government for Palestinians called Palestinian Authority (PA) and since that time the PA became responsible to serve Palestinian citizens in the West Bank and the Gaza Strip mainly, but also all Palestinians across the world (BBC 2008). More recently the General Assembly of the UN has granted Palestine a non-member observer state status which has resulted to a first real recognition for Palestine as a state (United Nations 2012).

\subsection{The need for e-government for Palestine:}

Many Palestinians are currently denied entry to Palestine because of the occupation control. At present Palestinians are living in different areas around the world where there are differences in terms of ICT infrastructure, Internet availability and IT literacy. This situation has resulted in significant problems in terms of accessing public services, communication with government agencies and participating in general elections. Since 2001 the Palestinian government has started an e-government initiative to address such problems.

Implementing e-government in Palestine may solve most of the problems in accessing public services and communication with government agencies. Considering the exceptional dispersion of the Palestinian population and Israel's control of the area, implementing real electronic government may enable the government to fulfil their responsibilities towards all Palestinians and provide public services electronically to Palestinians and other stakeholders. Moreover, it will facilitate democracy by removing the need for physical voting stations which is one of the main barriers to holding a conventional election in an inclusive way for all Palestinians.

The Palestinian Government's policy over the last few years has included e-government as one of the top national priorities. President Abbas had assigned a Ministerial Committee for E-Government. This committee had produced the first comprehensive E-government strategic Plan in 2005, and this document was part of the PA's vision "to provide a better life for our citizens by being a Government that: Empowers citizens to participate in government; Connects citizens, the private sector and institutions to drive economic growth and meet community challenges; and Delivers real public value through citizen-centric 
government services." (Organization for Economic Co-operation and Development (OECD), 2011).

According to the OECD, the e-government vision and policy for Palestine in 2010 had included "a public sector that provides citizens with high quality services and value for money". This plan states that the e-government National Strategy should, over time, work to increase efficiency and effectiveness of public service delivery; it also states that the Ministry of Telecommunications and Information Technology (MTIT) is the key player in terms of moving this initiative forward. Moreover, the 13th government program (Ending the Occupation, Establishing the State and Homestretch to Freedom) clearly mentions that the use of ICT and e-government in particular should help public sector reform and this is one of the most important national priorities (Organization for Economic Co-operation and Development (OECD) 2011).

Dr Sabri the Palestinian presidential adviser for ICT stated that Palestine has achieved a good level of e-transformation in terms of the moral will and spirited desire, but is still in the very early stages of implementing a real e-government project due to several barriers. These include geo-politics, legislation, decision-making policies and even awareness in terms of level of readiness to embrace and stimulate the digital transformation towards true digital government (Wafa, 2013). Dr Chadwick further commented that the implementation of egovernment in Palestine will solve all the problems in terms of accessibility and communication obstacles for Palestinian citizens living under Israeli occupation. Currently, the e-government project in Palestine is still suffering from various factors such as administrative complexities, interior complexities, problems of cooperation and data exchange between government institutions and in data accessibility (Wafa, 2013).

\subsection{An e-voting system for Palestinians:}

Since 1948, persons self-identified as "Palestinian" have scattered to countries across the world. This forced diaspora creates particular challenges as the Palestinian Authority (PA) continues to gain international recognition as an emerging state. With the potential of democratic elections and a fully recognized Palestinian state on the horizon, it becomes imperative that officials within the existing Palestinian Authority need to find new and innovative ways to engage a scattered constituency in the democratic process. To this end, some suggest that E-Democracy, using computer and internet technology to foster citizen participation in government, could afford a displaced constituency greater access to the workings of the emerging state (Tsagarousianou et al, 1998).

Due to the spread of Palestinians in different countries, the Palestinian Authority has experienced a huge difficulty in enabling its citizens to elect their representatives. Using a democratic way to elect people's representatives will be an ideal way to solve the Palestinian leadership crisis. According to government officials many countries who are hosting Palestinians as refugees do not allow elections to elect representatives to the PA government to take place in their jurisdiction. To overcome this difficult problem many researchers suggest e-voting systems as a solution.

Palestinian activists across the world have started an initiative for general elections that would engage Palestinians across the world. This initiative is based on years of campaigning and organization among Palestinians across the world, seeking a representative national institution that reflects the demands and positions of its people. It is based on three components: (1) a popular demand around which Palestinian communities in the homeland and outside have mobilized, (2) the nationally expressed consensus and (3) the official policy of the PLO, and the National Reconciliation Committee comprised of all the parties. The basis for the demand lies in the PLO's own fundamental laws; national positions such as the Prisoners Document of 2006, the various agreements of the National Reconciliation 
Committee in Cairo in 2010, 2011, and 2012; and the demands from hundreds of public meetings convened by Palestinians abroad, during earlier refugee mobilisations from 2003 to 2006. Leaders from the main Palestinian parties and factions, in addition to independents and intellectuals, have also encouraged Palestinians around the world to register to vote in this civic campaign in the National Call for Registration for PNC elections.

In June2011, a Palestinian organization called the Facilitation Office (FO) of the civic registration announced that they have finalized a secure electronic voter registration machine for PNC elections. In their statement they said "The technical, procedural, and political work that has gone into creating this registration mechanism makes it possible for all Palestinians to now register to vote for their national parliament, the Palestinian National Council (PNC)"

"The registration mechanism was built to provide Palestinians, in a variety of different locations and circumstances, with the opportunity to register to vote; whilst maintaining the highest international standards of safety and security in the creation of this primary register. The procedure of the registration process is simple: Palestinian civic associations wishing to run a voter registration drive can do so through a secure low-cost process, as part of a popularly-driven, national initiative"

"The procedures applied reflect international best practice and standards, and have been developed in agreement with the relevant national and international institutions to ensure equality of principle and practice across our exile and refugee communities, mindful of the obstacles and challenges faced by each"

Months later the central election commission in Palestine announced that an e-voting system is not applicable for the case of Palestine. They stated that the majority of Palestinian will not trust e-democracy.

\section{E-voting in Palestine - A Questionnaire Survey}

In response to the above announcement by the central election commission in Palestine and to gauge the interest and primarily trust in e-voting systems among Palestinians, the first author prepared a questionnaire survey. This was a first attempt to establish a scientifically researched view of Palestinian feelings towards any potential plans to introduce e-voting for elections in Palestine. The questionnaire served an additional purpose, to provide a first measure of how much interest such systems may attract across the Palestinian diaspora on a world-wide scale.

The questionnaire was setup using the popular survey tool http://www.questionpro.com/ . This offers data capture and data analysis facilities and the results shown below have been obtained using this tool.

\subsection{Results Analysis}

The first figure is a screenshot that shows the distribution of the responders across the globe. The response rate was quite high as this questionnaire was available for a short period of time in the early days of 2015. The statistics show a very high return rate of 320 completed responses out of the 860 views and a $73 \%$ completion rate among those who have started responding to the questionnaire. The actual rates could be much higher as a person that has completed the survey might have done so after 2 or more views, or someone that has eventually completed the survey might have had to abandon it and come back a second time. Overall the participation and completion result was very good as this survey was not sent to specific individuals but links to it were posted on social media and websites that are of interest to Palestinians. Thus the completion numbers and rates alone show that there is interest in e-voting systems among Palestinians who are keen to express their approval or not of such systems. A further piece of information available in figure 1 is 
the spread of respondents on a worldwide scale. Naturally nearly $37 \%$ reside in Palestine, but there is a good contribution to the survey from countries in Europe, neighbouring countries to Palestine and as far as the USA. A further element of information is that showing the diversity of devices used to access the survey, which could potentially indicate the level of familiarity with technology and possibly a likelihood of trusting e-voting systems.

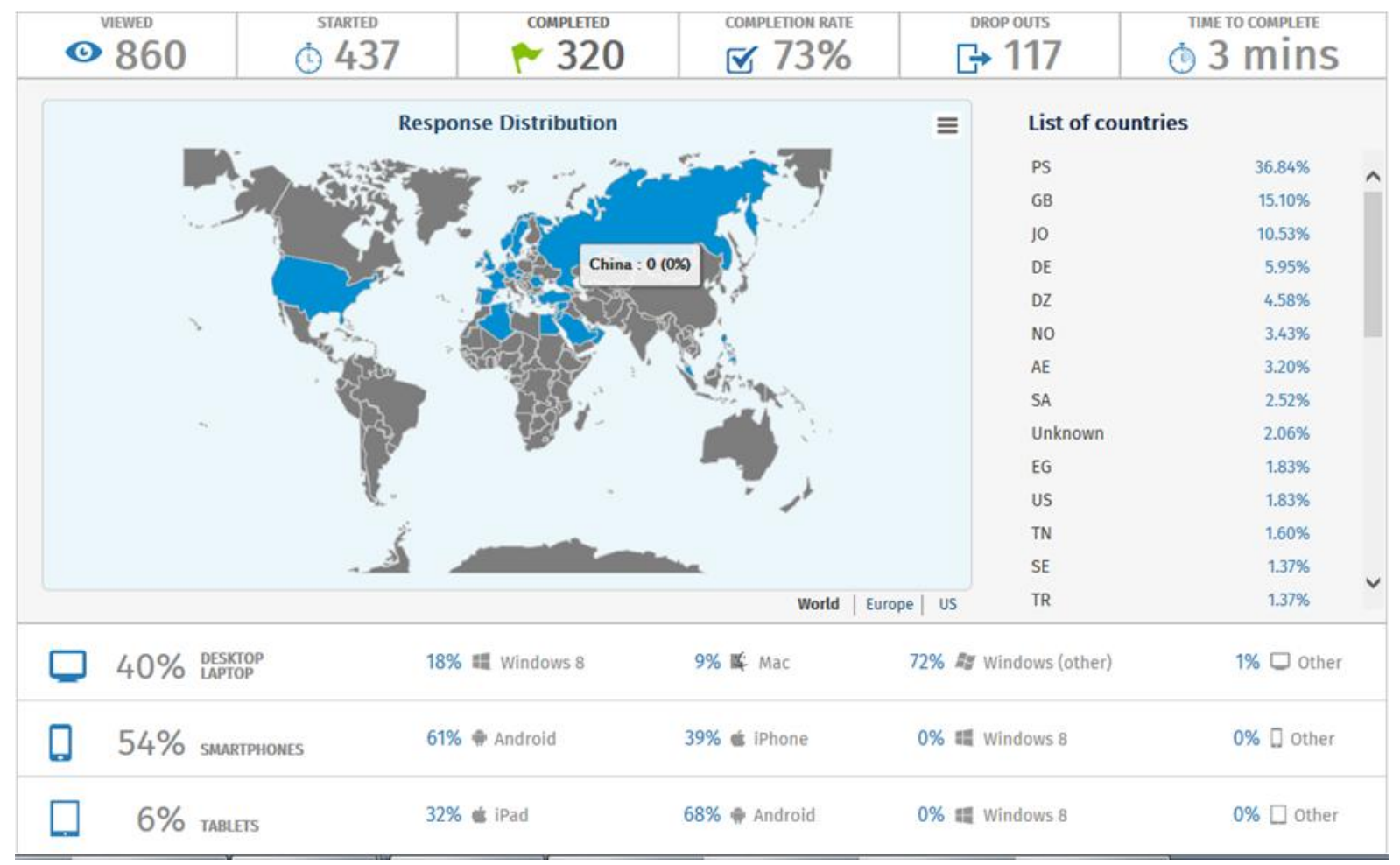

Figure 1. Response Distribution \& Access Media

To gauge the respondents level of trust in technology, something that could reflect on the likelihood of accepting and trusting e-voting systems, figures 2 and 3 show their experience with and frequency of using the internet respectively. The two figures indicate that the overwhelming majority of the respondents are experienced users who use the internet very frequently. This may demonstrate a slight bias, as clearly the respondents represent a segment of the Palestinian society that is well educated and have access to the internet. One could ask whether this is representative of the Palestinian society, but any scepticism should be reserved as the objective of engaging e-voting systems is to enable Palestinians that live outside the areas controlled by the Palestinian Authority (PA) to participate in elections. From that point of view the results are very encouraging as $63 \%$ of the respondents reside away from the lands controlled by the PA. 


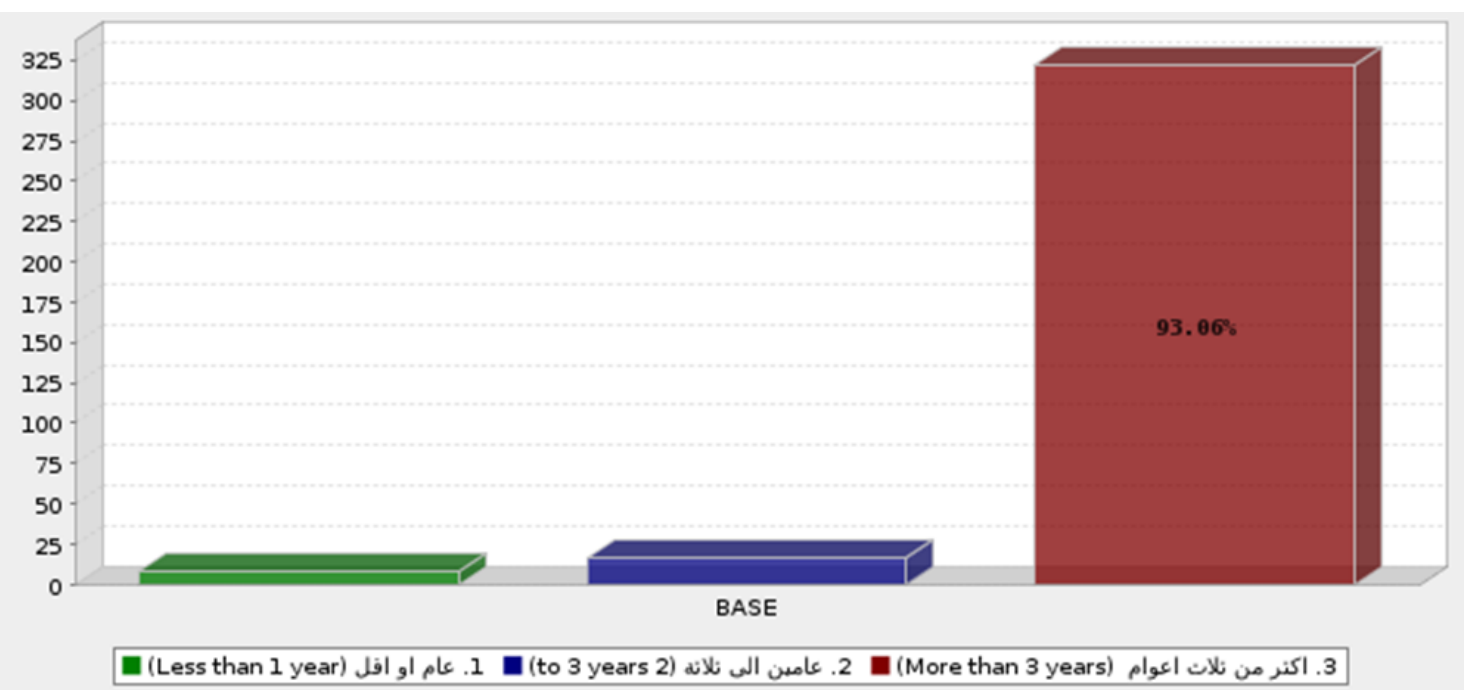

Figure 2. Length of use of the Internet

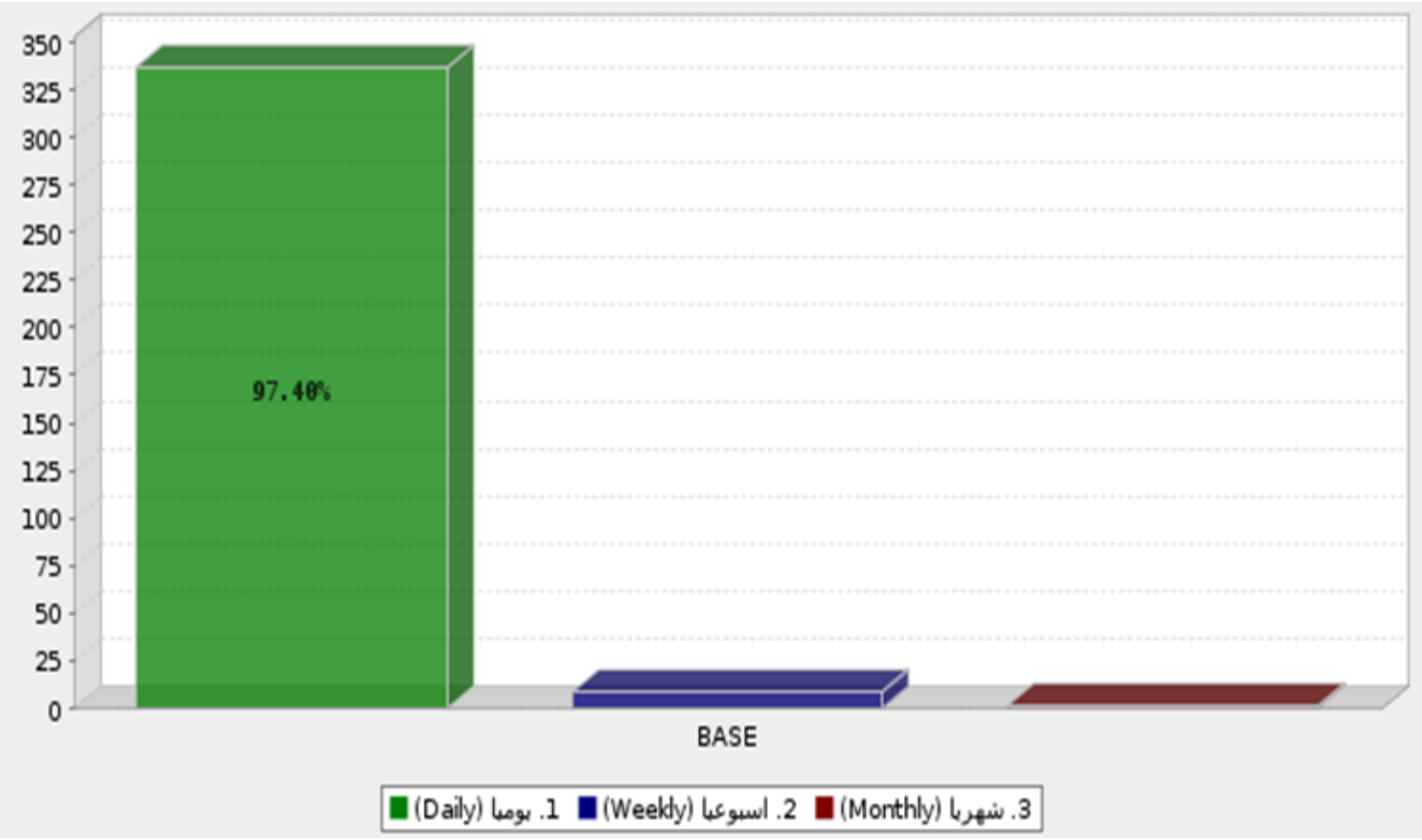

Figure 3. Frequency of use of the Internet

The data shown in figure 4 below captures the purpose of use of the internet and thus possibly the level of knowledge and the level of exposure to critical applications available online. As can be seen the majority of the respondents are users of systems that provide secure access to their online services (email, e-shopping, social networks and educational systems). This indicates that these respondents are accustomed to accessing secure systems and that they have developed a considerable level of trust to such systems. Hence they will be more likely to accept the use of e-voting systems and participate in online elections (Quental and Borges Gouveia, 2014). 


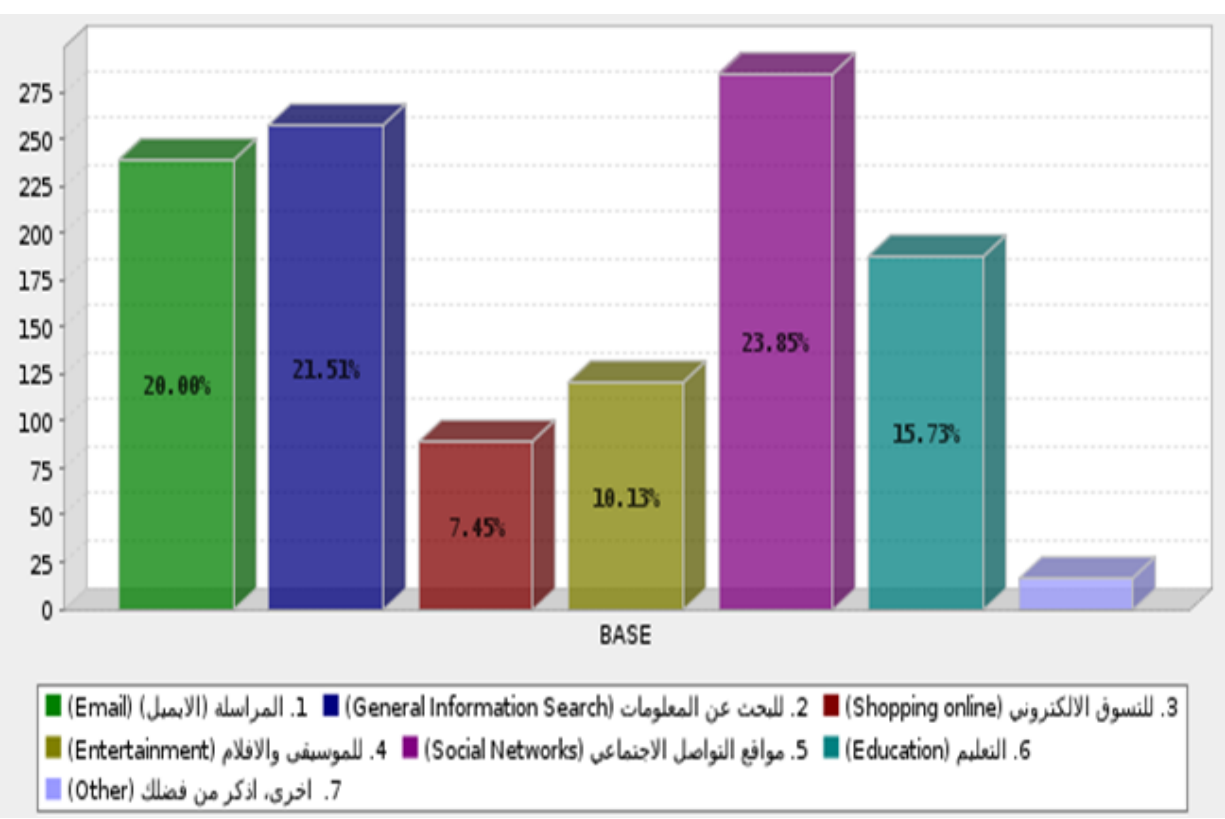

Figure 4. Purpose of using the Internet

The graphical representation of the responses in figure 5 shows the willingness of the respondents to use e-government services. This is a key question as any e-voting system that aspires to enjoy any credibility and to provide appropriate authentication and verification systems will have to be accessed through government services. The figures relating to the graph show a high majority of the respondents, more than $75 \%$, to be ready to trust and use e-government services, while a further $15 \%$ appears to be neutral. Often neutrality is linked to lack of knowledge or of experience and in such cases the provision of suitable information and services relevant to the users' needs might sway the public. The negative stance against e-government services represents only $10 \%$ of the recorded views and it appears that is not enough to alter the positive attitude towards e-government. This is a very encouraging sign for those sponsoring and supporting the move to e-government services provision by the PA.

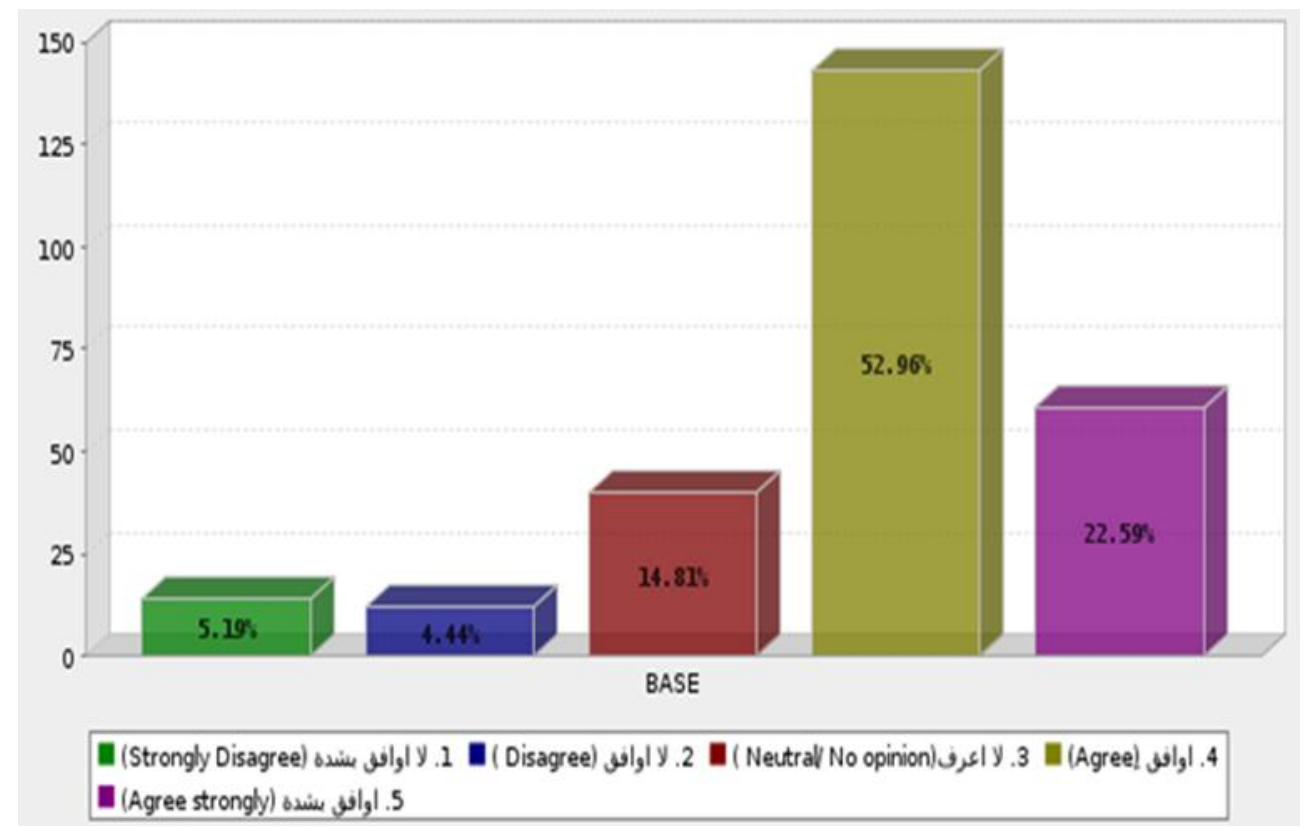


The final two figures present the response to the most critical and possibly the most challenging questions in this survey, namely whether Palestinians feel inclined to trust evoting systems. Figures 6 and 7 include two diagrams that depict two different facets of an answer to practically the same question relating to trust. Figure 6 represents the attitude towards using e-voting systems and here the positive responses amount to nearly $66 \%$, while the definitely negative responses reach $25 \%$ a score that is much higher than those opposed to e-government services.

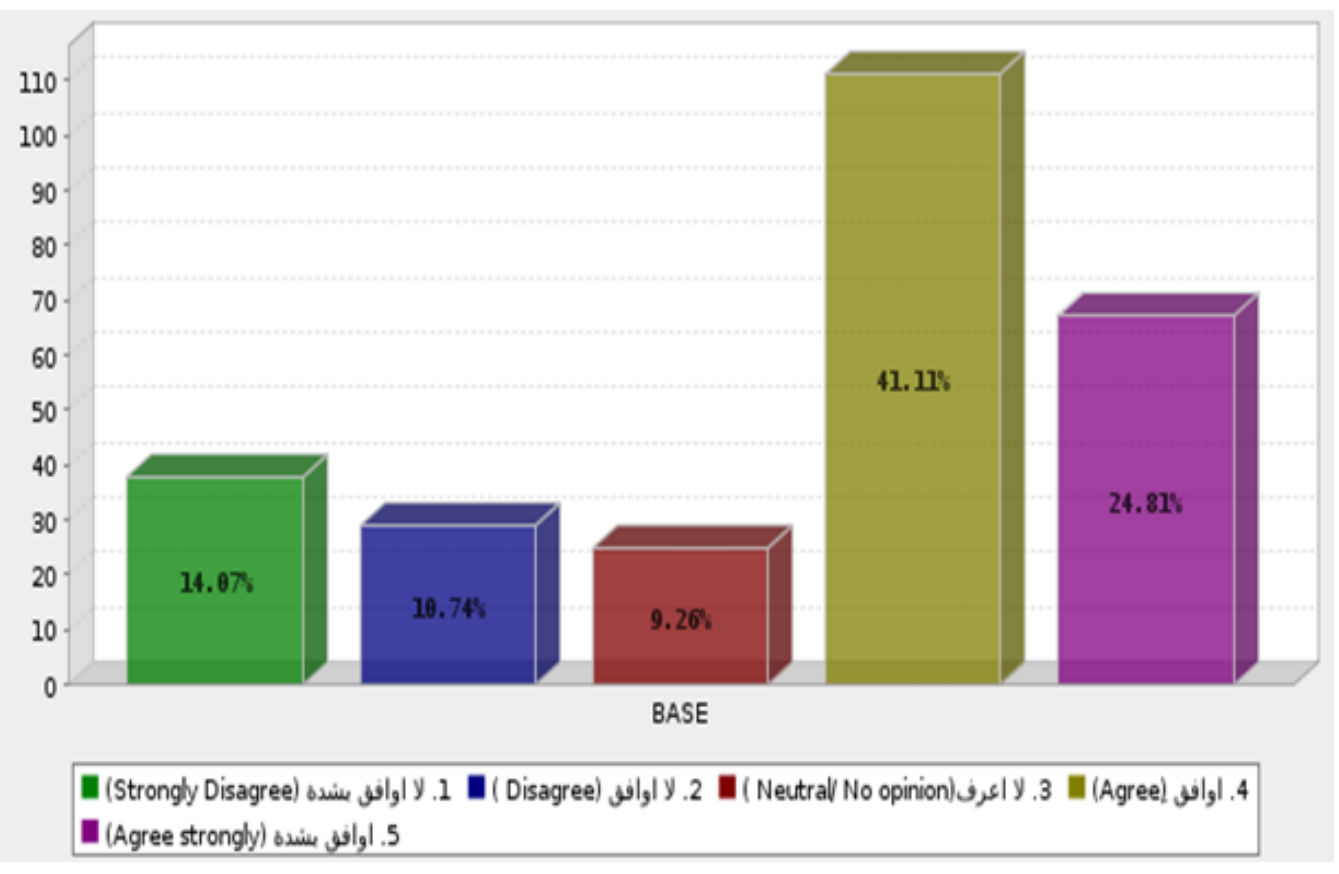

Figure 6 . Willingness to use e-voting systems

The diagram in figure 7 shows an even more interesting angle to the responses only just $52 \%$ of respondents seem ready to trust e-voting systems in leading to a solution for a more participatory general election. At the same time those respondents that have shifted from the positive attitude towards using e-voting systems have not all moved to the negative position camp. A lot of them seem to have stayed at a neutral ground. This might mean that there is some confusion or even mistrust as to whether there could be any real benefits accrued from e-voting systems, while citizens are prepared to use them out of the necessity to participate in the election process. Clearly if the case for e-voting in Palestine were to gain momentum, citizens will need to be attracted by services that will offer them the ability to directly engage in decision-making. In a population that has often been deprived, either by distance or due to politics, from engaging with their government and the governance of their land the level of trust should be easily gained if the right services were to be established before e-voting was introduced. If this does not take place then the same level of disappointment that can be observed in European countries (Quental and Borges Gouveia, 2014) will be encountered in Palestine and more Palestinians will disassociate themselves with e-services and e-voting. 


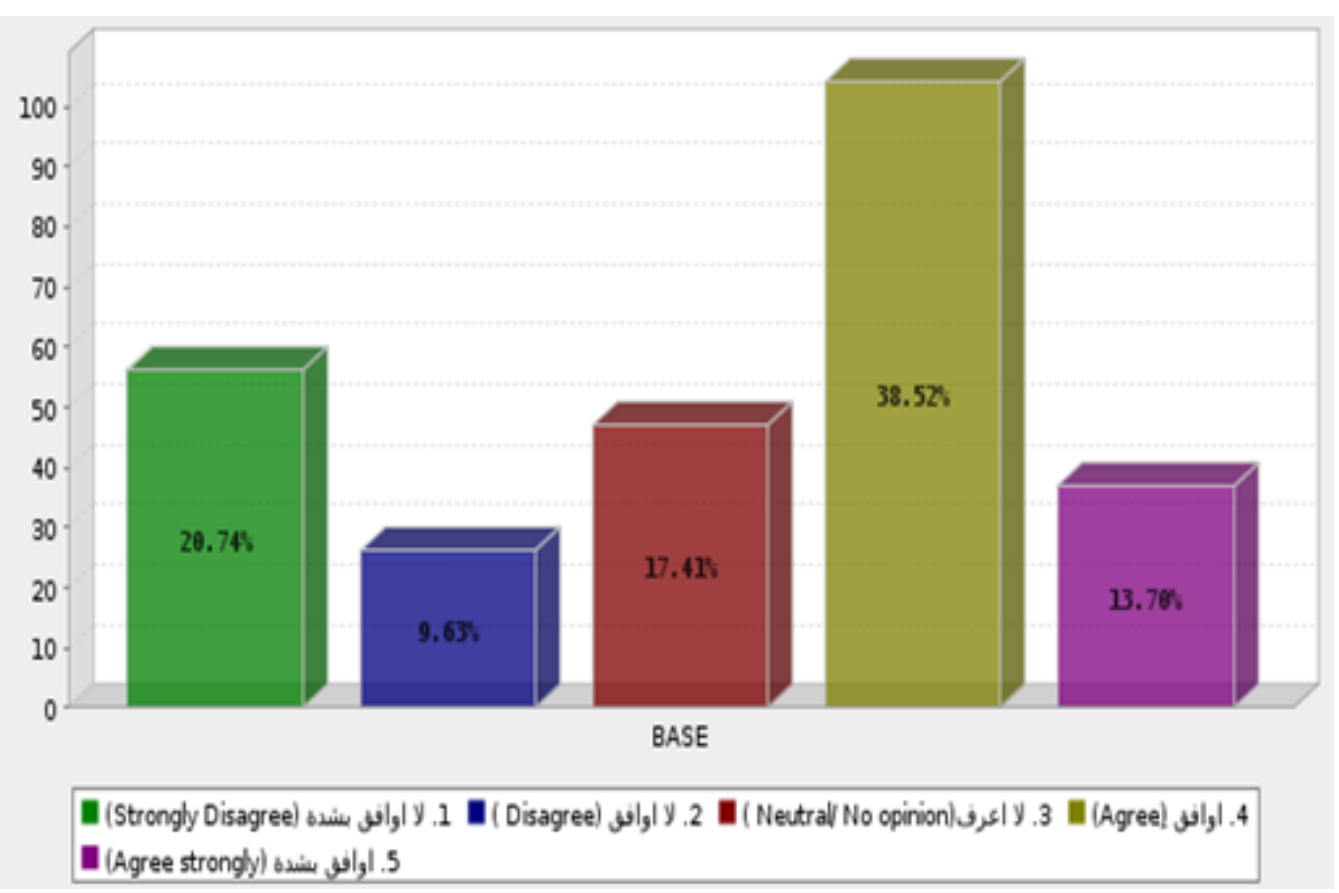

Figure 7. Level of Trust in e-voting systems

The authors do not believe that the outcomes of this first survey can convey a definitive message / conclusion as to the acceptance of and / or suitability of e-voting as a solution to elections in Palestine. More work is required and as such, the use of social media as means for engaging in political debate needs to be explored. The level of commitment, trust and privacy often offered by anonymity in the use of social media should be explored.

Particularly the protection of identity could prove a key aspect of development of trust and acceptance of e-voting systems. This would in turn allow for further use of analytics that could enhance the potential of the state being empowered to deliver citizen defined services which in turn enhance e-engagement and eventually lead to true e-democracy.

\section{E-Voting and e-Democracy fulfilment - Impact on a World in Crisis}

This survey has shown some important findings relating to Palestine. The authors though feel that these results and the momentum of this work are not restricted to Palestine and Palestinians alone. At the time of writing, the world and Europe more specifically is experiencing unprecedented numbers of forced migrants fleeing war zones and seeking asylum (BBC, 2016a and BBC, 2016b). Countries across Europe have resorted to unpopular measures to stave off illegal migration while they assess the different cases (The Guardian, 2016). Once all the rightful asylum seekers get settled in new lands they'll still need to engage with their home country and possibly participate in the reinstitution of democracy in the homeland. If systems such as cross border e-government services can be used to manage those sensitive populations they'll slowly develop trust through protected privacy and they'll embrace e-services eagerly (Sideridis et. al. ,2015). The next step towards edemocracy will then be the use of e-voting systems that will lead to dynamic e-participation in the future of their homeland. Such systems could in turn introduce transparency and lead to the ultimate goal of e-democracy in countries where this is not currently possible through the use of conventional / traditional systems.

If e-voting will work in Palestine it can work in a lot of places where democracy has suffered significantly, mistrust for the political system is rife and people have been misplaced. As 
stated previously the authors have only explored part of the relationship between technological solutions and the building of trust in this work. There is still work to be completed in other aspects of such a relationship. Even when that part of the work is complete there is a further social / political element that needs to be considered, that of government agreement and willingness to participate and offer a fully transparent electoral environment. This cannot be developed by any technology and cannot be engineered by scientists. It is the work of politicians and international organizations. The authors do not claim to have expertise to support such work and hence restrict themselves to studying the technological solutions that might offer the right support for when the political environment has been rendered ripe for such transition.

This work is not yet complete. It is rather the start of a long journey to explore, develop deep knowledge of the reasons for resistance, design and develop e-services that build trust, engage citizens, build a spirit of e-participation and eventually deliver transparency that would support the pathway to true e-democracy.

\section{References}

Aumann, Y., and Lindell, Y. (2010)Security against covert adversaries: efficient protocols for realistic adversaries. J. Cryptology 23(2), 281-343

BBC 2016a. [online] http://www.bbc.co.uk/news/world-europe-34131911/ (accessed 02/05/2016)

BBC 2016b. [online] http://www.bbc.co.uk/news/world-europe-36054840/ (accessed 02/05/2016)

BBC, 2008-last update, 1993 Oslo agreement. Available:

http://news.bbc.co.uk/1/hi/world/middle_east/7385301.stm (accessed 10/01/2016).

Bhoyar, K., Patil, P.R., Zaware, A.R. and Pawar, A.S. (2015) An Assurable E-Voting System

That Ensures Voter Confidentiality and Voting Accuracy, International Journal of Computer Applications, Volume 132 - No.14, pp. 18-21.

Buccafurri, F., Fotia, L. and Lax, G. (2015) A privacy-preserving e-participation framework allowing citizen opinion analysis, Electronic Government, an International Journal (EG), Vol. 11, No. 3, 2015, pp.185- 206.

Casati, R. (2009) Trust, secrecy and accuracy in voting systems: the case for transparency. Mind \& Society, 9(1), pp.19-23

Celeste, R., Thornburgh, D. and Lin, H. (2006) Asking the right questions about electronic voting. Washington, D.C.: National Academies Press.

e-kathimerini.com (2015) New Democracy calls off leadership vote due to IT problems, http://www.ekathimerini.com/203673/article/ekathimerini/news/new-democracy-calls-offleadership-vote-due-to-it-problems, (accessed 05/05/2016)

Kiayias, A., Zacharias, T. and Zhang, B. (2015) On the Necessity of Auditing for Election Privacy in e-Voting Systems, S.K. Katsikas and A.B. Sideridis (Eds.): E-Democracy 2015, CCIS 570, pp. 3-17, Athens, Greece 
Kim, S., Lee, H. and Lee, M. (2015) A Study for Vulnerabilities Overcome in Electronic Voting System, International Journal of Software Engineering and Its Applications, Vol. 9, No. 8, pp. $1-14$

Mukhametzhanova, A., Harvey, R. and Smith, D. (2014) Ahead in the G-clouds: Policies, Deployment and Issues, Electronic Government and the Information Systems Perspective, Third International Conference, EGOVIS 2014, Munich, Germany, September 1-3, 2014. Proceedings, Springer, LNCS Vol. 8650, pp. $292-306$.

ORGANIZATION FOR ECONOMIC CO-OPERATION AND DEVELOPMENT (OECD), 2011-last update, THE CASE OF E-GOVERNMENT IN THE PALESTINIAN AUTHORITY. Available: http://www.google.co.uk/url?sa=t\&rct=j\&q=\&esrc=s\&source=web\&cd=1\&ved=0CCYQFjAA\& url=http\%3A\%2F\%2Fwww.oecd.org\%2Fmena\%2Fgovernance\%2F50402812.pdf\&ei=pA9mVP XALPPraOuRgegO\&usg=AFOjCNGcKbO_f5m4r2jCfZAsqtdzSfiDLw (accessed 11/12/2014).

OECD (2003) Promise and Problems of E-Democracy: Challenges of Online Citizen Engagement

Pimenidis, E. and Georgiadis C.K. (2014) Can e-Government Applications Contribute to Performance Improvement in Public Administration?, International Journal of Operations Research and Information Systems, 5(1), 48-57

Pimenidis E, Sideridis A.B, Antonopoulou E (2009) Mobile Devices and Services: Bridging the Digital Divide in Rural Areas, International Journal of Electronic Security and Digital Forensics (IJESDF), Vol. 2, No. 4, pp. 424-434

PSC, 2014-last update. Available: http://www.palestinecampaign.org/information/ (accessed 15/12/ 2014).

Quental, C. and Borges Gouveia, L. (2014) Web Platform for Public E-Participation Management: A Case Study, International Journal of Civic Engagement and Social Change, 1(1), 60-77, January-March 2014

Shat, F., Mousavi, S.,A.,A and Pimenidis, E. (2014) Electronic Government Enactment in a Small Development Country - The Palestinian Authority's Policy and Practice, in A.B.

Sideridis et al. (Eds.): E-Democracy 2013, CCIS 441, pp. 83-92, Athens, Greece

Shilbayeh, N.F., Al-Saidi, R.A. and Alsswey, A.H. (2016) Evaluation and Analysis of the Secure E-Voting Authentication Preparation Scheme (EV-APS), Proceedings ICCNS 2016: 18th International Conference on Cryptography and Network, Miami, USA, 24-25, March, 2016

Sideridis, A., Protopappas, L., Tsiafoulis, S. and Pimenidis, E. (2015) Smart cross-border e-Gov systems and applications. In: S.K. Katsikas and A.B. Sideridis (Eds.): E-Democracy 2015, CCIS 570, pp. 151-165, Athens, Greece 
The Guardian, EU relocates just 208 refugees from Greece after deal with Turkey [online] http://www.theguardian.com/world/2016/apr/15/eu-relocates-just-208-refugees-fromgreece-after-deal-with-turkey/ (accessed 15/04/2016)

Tsagarousianou, R., Tambini, D. and Bryan, C. (1998) Cyberdemocracy: Technology, Cities and Civic Networks. Routledge London.

UNITED NATIONS, 2014-last update, PLO

https://www.unescwa.org/sites/www.unescwa.org/files/ministerial sessions/resolutions/31 6xxviii.pdf (accessed 03/05/2017).

UNITED NATIONS, 2012-last update, General Assembly Votes Overwhelmingly to Accord Palestine 'Non-Member Observer State' Status in United Nations. Available: http://www.un.org/press/en/2012/ga11317.doc.htm (accessed 08/03/ 2015). 